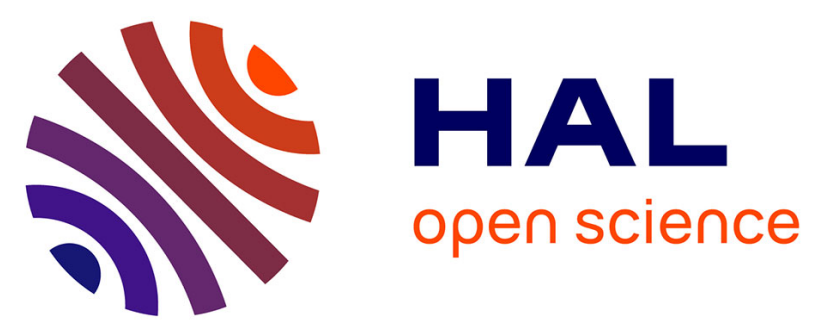

\title{
Dodecyl creatine ester and lipid nanocapsule: a double strategy for the treatment of creatine transporter deficiency.
}

Alexandra Trotier-Faurion, Catherine Passirani-Malleret, Jérôme Bejaud, Sophie Dézard, Vassili Valayannopoulos, Fréderic Taran, Pascale de Lonlay, Jean-Pierre Benoit, Aloïse Mabondzo

\section{To cite this version:}

Alexandra Trotier-Faurion, Catherine Passirani-Malleret, Jérôme Bejaud, Sophie Dézard, Vassili Valayannopoulos, et al.. Dodecyl creatine ester and lipid nanocapsule: a double strategy for the treatment of creatine transporter deficiency.. Nanomedicine (London, England), 2014, 10, pp.185-91. 10.2217/nnm.13.205 . hal-03179496

\section{HAL Id: hal-03179496 \\ https://univ-angers.hal.science/hal-03179496}

Submitted on 24 Mar 2021

HAL is a multi-disciplinary open access archive for the deposit and dissemination of scientific research documents, whether they are published or not. The documents may come from teaching and research institutions in France or abroad, or from public or private research centers.
L'archive ouverte pluridisciplinaire HAL, est destinée au dépôt et à la diffusion de documents scientifiques de niveau recherche, publiés ou non, émanant des établissements d'enseignement et de recherche français ou étrangers, des laboratoires publics ou privés. 


\section{Dodecyl creatine ester and lipid nanocapsule: a double strategy for the treatment of creatine transporter deficiency}

\begin{abstract}
Background: Creatine transporter (CT) deficiency is characterized by mutations in the gene encoding $\mathrm{CT}$, leading to impaired transport of creatine at the cell membrane. Patients with this disease would thus benefit from replenishment of creatine inside the brain cells. Aim: We report a therapeutic strategy based on the use of dodecyl creatine ester incorporated into lipid nanocapsules (LNCS). Materials \& methods: The dodecyl creatine ester was incorporated in the shells of LNCs using Transcutol ${ }^{\circledR}$ (Gattefossé SAS, Saint-Priest, France). The interactions of dodecyl creatine ester encapsulated in LNCs with an in vitro cell-based blood-brain barrier model was studied. The entry of the dodecyl creatine ester encapsulated in LNCs and the conversion of dodecyl creatine ester to creatine in the cells were also studied in the pathological context of CT deficiency. Results \& discussion: We showed that these LNCs can cross the blood-brain barrier and enter brain endothelial cells. In human fibroblasts lacking functional CT, all or part of the dodecyl creatine ester was released from the LNCs and biotransformed to creatine, thus indicating the value of this strategy in this therapeutic context.
\end{abstract}

Original submitted 2 April 2013; Revised submitted 28 October 2013

Keywords: blood-brain barrier $\bullet$ creatine $\bullet$ creatine transporter deficiency $\bullet$ dodecyl creatine ester • lipid nanocapsule

Creatine metabolism deficiencies result from either an enzymatic defect of creatine biosynthesis (arginine:glycine amidinotransferase and guanidinoacetate methyltransferase deficiencies by recessive autosomal transmission) or a defect in the transport of creatine through cell membranes (X-linked creatine deficiency caused by mutations in the $S L C 6 A 8$ gene) [1]. In both cases, patients suffer from severe developmental disabilities with language delay, extrapyramidal syndrome, behavioral disorders and sometimes epileptic seizures [2-4]. Therapies based on creatine supplementation or on creatine precursors L-arginine and L-glycine significantly improve creatine biosynthesis deficiencies, in terms of both clinical and biochemical findings. However, in a 4- to 6 -year follow-up of patients suffering from the creatine transporter deficiency, there was no clinical progress or increase in intrain a clinical situation where the absence of a functional creatine transporter at the blood-brain barrier (BBB) and in the brain parenchyma cells, particularly in neurons and astrocytes, prevents the entry and diffusion of creatine in the CNS [6-8]. Therefore, an evaluation of new therapeutic strategies for this cerebral metabolic disorder is now necessary. We previously reported that dodecyl creatine ester would be a good drug candidate to develop as a therapeutic option for patients suffering from creatine transporter deficiency $[9,101]$. However, dodecyl creatine ester would be degraded by plasma esterases in all biological fluids. An efficient delivery system that targets dodecyl creatine cerebral creatine levels [5]. Patients are thus
Alexandra Trotier-Faurion ${ }^{\ddagger 1}$, Catherine Passirani ${ }^{2,3}$, Jérôme Béjaud $^{\ddagger 2,3}$, Sophie Dézard ${ }^{4}$, Vassili Valayannopoulos ${ }^{5}$, Fréderic Taran 4 , Pascale de Lonlay ${ }^{5}$, Jean-Pierre Benoit ${ }^{2,3}$ \& Aloïse Mabondzo*1

${ }^{1}$ CEA, Direction des Sciences du Vivant, iBiTec-S, Service de Pharmacologie et d'Immuno Analyse, Equipe Pharmacologie Neurovasculaire, Gif-sur-Yvette, France

${ }^{2}$ L'Université Nantes Angers Le MansUniversité d'Angers, F-49933, Angers, France

3INSERM U1066-Micro et

Nanomédecines Biomimétiques, Angers, France

${ }^{4}$ CEA, Direction des Sciences du Vivant, iBiTec-S, Service de Chimie Bio-organique et de Marquage, Gif-sur-Yvette, France

${ }^{5}$ Centre de Référence des Maladies Héréditaires du Métabolisme de l'Enfant et de I'Adulte, Hôpital Necker-Enfants Malades, Université Paris Descartes, Paris, France

*Author for correspondence:

Tel.: +33169081321

aloïse.mabondzo@cea.fr

${ }^{\ddagger}$ Authors contributed equally 
ester to the brain parenchyma has yet to be developed. By overcoming creatine transporter deficiency at the $\mathrm{BBB}$, it would enable the delivery of dodecyl creatine ester inside brain cells thus restoring the creatine pool and improving neuronal functions. Lipid nanocapsules (LNCs) have already been described as a promising approach to the specific delivery of lipophilic therapeutic agents [10-12], especially into the brain. Prepared according to a solvent-free process, these spherical LNCs made of biocompatible materials exhibit good stability in suspension. Their surface contains polyethylene glycol (PEG), which affects the vascular residence time of the nanocapsules, providing stealth properties. The PEG is contained in Solutol ${ }^{\circledast}$ HS15 (BASF, Levallois-Perret, France), used in the LNC preparation. The PEG is known to increase the vascular residence time of the LNCs and avoid the capture by the reticuloendothelial system. These two actions provide stealth properties to the LNC. This is required for an in vivo administration in order to get the best efficiency. Unpublished findings from our laboratory demonstrate that such LNCs cross the $\mathrm{BBB}$ in an in vitro cell-based rat model [Trotier-Faurion A, Mabondzo A, Unpublished Data].

However, several investigations showed that the high susceptibility of dodecyl creatine ester to hydrolysis in aqueous media at high temperatures (above $37^{\circ} \mathrm{C}$ ) rendered it unsuitable for the standard LNC preparation process. In this study, Transcutol ${ }^{\circledR}$ (Gattefossé SAS, Saint-Priest, France) was used to dissolve the dodecyl creatine ester at ambient temperature and the mixture was added in the last heating step. Transcutol has interesting surfactant properties [13] and is thus incorporated into the shell of LNCs. The LNCs produced (dodecyl creatine ester encapsulated in LNCs [LNC-C12]) have properties suitable for intravenous injection (size: $48.31 \pm 1.77 \mathrm{~nm}$; polydispersity index: $0.07 \pm 0.01$; zeta-potential: $-0.17 \mathrm{mV}$; LNC-C12 theoretical concentration: $260 \mathrm{mg} \cdot \mathrm{ml}^{-1}$; and theoretical concentration of dodecyl creatine ester: $300 \mu \mathrm{g} \cdot \mathrm{ml}^{-1}$ ). We then studied the translocation of LNC-C12 across an in vitro cellbased rat BBB model [14] and the delivery of dodecyl creatine ester in endothelial and astroglial cells. We investigated whether, in the pathological context of creatine transporter deficiency, entry of LNC-C12 is possible and would result in an increase of the creatine pool in the cells.

\section{Materials \& methods}

Dodecyl creatine ester synthesis

Dodecyl creatine ester was synthesized according to a process patented in July 2012 and experiments were conducted as described previously [9]. Briefly, the first step consisted of an activation of the electrophilicity of the carbonyl moiety of creatinine by double protection of the cyclic guanidine (carbamate derivative). Then, in the presence of dodecanol, the creatinine ring opened spontaneously. A carbamate deprotection generated dodecyl creatine ester [9].

\section{Preparation of LNCS}

LNCs were prepared according to Heurtault et al. [15] with a minor modification derived from Roger $e t$ al. 2011 [13], consisting of the solubilization of $300 \mu \mathrm{g}$ of dodecyl creatine ester in Transcutol added at the last heating step. Briefly, $0.3 \mathrm{~g}$ of Labrafac $\mathrm{CC}^{\circledR}$ (Gattefossé SAS), $0.9 \mathrm{~g}$ of Labrafil M1944CS ${ }^{\circledR}$ (Gattefossé SAS), $1.0 \mathrm{~g}$ of Solutol HS15, $0.1 \mathrm{~g}$ of $\mathrm{NaCl}$ and $1.8 \mathrm{~g}$ of 4-(2-hydroxyethyl)-1-piperazineethanesulfonic acid buffer were heated at $90^{\circ} \mathrm{C}$ under magnetic stirring, then cooled to $60^{\circ} \mathrm{C}$. Two cycles of progressive heating and cooling between 60 and $90^{\circ} \mathrm{C}$ were then performed. At $90^{\circ} \mathrm{C}$, just before the last cooling, $0.3 \mathrm{~g}$ of Transcutol containing the dodecyl creatine ester was added and at $75^{\circ} \mathrm{C}$ an irreversible shock was induced by dilution with cold 4-(2-hydroxyethyl)-1-piperazineethanesulfonic acid buffer $\left(5.6 \mathrm{ml}\right.$ at $\left.2^{\circ} \mathrm{C}\right)$. The LNCs were analyzed for size distribution by photon correlation spectroscopy and zeta-potential using the Malvern Zetasizer ${ }^{\circledR}$, NanoSeries ZS (Malvern, Orsay, France) after filtration through a $0.20-\mu \mathrm{m}$ filter from Sartorius (Les Ulis, France). The theoretical payload was $300 \mu \mathrm{g}$ in $1 \mathrm{~g}$ of LNC suspension and the encapsulation efficiency was $90 \%$ corresponding to a final loading of $270 \mu \mathrm{g} / \mathrm{g}$ of the drug.

\section{In vitro studies}

\section{BBB translocation of LNC-C12}

The in vitro cell-based BBB model consisted of a co-culture of primary rat endothelial and astroglial cells. Primary rat astroglial cells were seeded at a density of $2 \times 10^{4}$ cells/well in $1500 \mu \mathrm{l}$ on a 12 -well plate. The astroglial culture medium was a mixture of minimum essential medium- $\alpha$ and Ham's F-12 nutrient mixture supplemented with 5\% fetal bovine serum, 1\% human serum, $1 \%$ penicillin/ streptomycin/neomycin and $0.4 \%$ FGF. A total of 24 h later, Costar ${ }^{\circledast}$ Transwell $^{\circledast}$ (Sigma-Aldrich, SaintQuentin Fallavier, France) inserts (pore size $0.4 \mu \mathrm{m}$; diameter $12 \mathrm{~mm}$; surface area $1.12 \mathrm{~cm}^{2}$ ) were placed inside the wells and primary rat endothelial cells were plated on the upper layer at a density of $8 \times 10^{4}$ cells/insert in $500 \mu \mathrm{l}$ endothelial basal medium-2 supplemented with the $\mathrm{EGM}^{\circledR}-2 \mathrm{MV}$ kit (Lonza, Levallois-Perret, France). The chambers containing endothelial cells and astroglial cells were considered as the apical and basolateral compartments, respectively. 
The plates were incubated at $37^{\circ} \mathrm{C}$ in an atmosphere containing $5 \% \mathrm{CO}_{2}$ and the $\mathrm{BBB}$ model formed confluent monolayers within 12 days [14,16]. After 12 days, the integrity of this BBB model was assessed. The apical and basolateral media were replaced by specific transport buffer $(150 \mathrm{mM} \mathrm{NaCl} ; 5.2 \mathrm{mM} \mathrm{KCl}$; $2.2 \mathrm{mM} \mathrm{CaCl} ; 0.2 \mathrm{mM} \mathrm{MgCl} ; 6 \mathrm{mM} \mathrm{NaHCO}$; $2.8 \mathrm{mM}$ glucose and $5 \mathrm{mM}$ 4-(2-hydroxyethyl)-1piperazineethanesulfonic acid) without (negative control, vehicle) or with LNC-C12 dissolved at 2,5 and $10 \mathrm{mg} \cdot \mathrm{ml}^{-1}$. After $60 \mathrm{~min}$ of incubation, cells' incubation media were diluted fivefold in 95\% acetonitrile $/ 5 \%$ formic acid and cells were scraped in a mixture of $20 \%$ water $/ 76 \%$ acetonitrile $/ 4 \%$ formic acid. After centrifugation $\left(13,000 \times g, 10 \mathrm{~min}, 4^{\circ} \mathrm{C}\right)$, HPLC tandem mass spectrometry was used to detect the dodecyl creatine ester in each compartment and in endothelial and astroglial cell lysates. The integrity of the cell-based BBB models was demonstrated by measuring the flux of $\left[{ }^{14} \mathrm{C}\right]$-sucrose, $\left[{ }^{3} \mathrm{H}\right]$-vinblastine and $\left[{ }^{3} \mathrm{H}\right]$-propranolol through the monolayer. Transwells with rat endothelial cell monolayers were transferred to new 12-well plates. A specific transport buffer was added: $500 \mu$ l to the apical compartment and $1500 \mu \mathrm{l}$ to the basolateral compartment. After $60 \mathrm{~min}$ of incubation at $37^{\circ} \mathrm{C}$ of $0.1 \mu \mathrm{Ci} \cdot \mathrm{ml}^{-1}\left[{ }^{14} \mathrm{C}\right]$-labeled sucrose, $1 \mu \mathrm{Ci} \cdot \mathrm{ml}^{-1}\left[{ }^{3} \mathrm{H}\right]$-propranolol in the apical compartment and $0.1 \mu \mathrm{Ci} . \mathrm{ml}^{-1} \quad\left[{ }^{3} \mathrm{H}\right]$-vinblastine in the apical and basolateral compartment, cells' incubation media from both apical and basolateral compartments were collected. The amount of tracer that passed through the endothelial monolayer was determined by scintillation counting and the permeability of each compound $\mathrm{X}$ from the apical to the basolateral compartment $\left(P_{a p p} X_{A \rightarrow B}\right)$, and was assessed using Equation 1:

$$
P_{a p p} X_{A \rightarrow B}=\frac{\left[X_{\text {basslateral }}\right] \times V_{B}}{T \times S \times\left[X_{0}\right]}(\text { Equation } 1)
$$

where $X$ is the compound for which the permeability is assessed, $\left[X_{\text {basolateral }}\right]$ is the concentration of the compound $X$ in the basolateral compartment at the end of the incubation, $V_{B}$ is the total volume of the basolateral compartment $(1.5 \mathrm{ml}), T$ the time of the incubation, $S$ is the transwell surface area and $\left[X_{0}\right]$ is the concentration of compound $X$ at initial time, $\mathrm{T}_{0}$. Validated BBB models have sucrose permeability below $8 \times 10^{-6} \mathrm{~cm} \cdot \mathrm{s}^{-1}$, propranolol permeability above $16 \times 10^{-6} \mathrm{~cm} \cdot \mathrm{s}^{-1}$ and a vinblastine permeability ratio above 2 .

The Lucifer yellow (LY) permeability test was used to study the effect of LNC-C12 on BBB integrity. LY was diluted in transport buffer to a final concentration of $100 \mu \mathrm{M}$ and added to the apical compartment during LNC-C12 incubation. Fluorescence leakage was determined for LY with $485 \mathrm{~nm}$ excitation and $530 \mathrm{~nm}$ emission using a fluorescence plate reader. The LY permeability was then calculated: a value below $5 \times 10^{-6} \mathrm{~cm} \cdot \mathrm{s}^{-1}$ indicated that the LNC-C12 did not damage BBB integrity.

\section{Uptake of LNC-C12 in fibroblasts}

Human fibroblasts were obtained from skin biopsy specimens, a gift from the Centre de Référence des Maladies Héréditaires du Métabolisme at the Necker Hospital (Paris, France). Three patients with cerebral creatine deficiency caused by lack of creatine transporter and one control patient were studied. All of the mutations were previously described by Valayannopoulos et al. in 2013 [17]: p.Asn336del c.1006_1008delAAC (patient 1, DTp1) and p.(Gly499del) c.1497_1500delGAG (patient 2, VLp2) as P3 and P4, respectively, or by Valayannopoulos et al. in 2012 [18] as P2 for p.(G414del) c.1221_1223delTTC (patient 3, CTp3). The fibroblasts were plated out at 30,000 cells per well in six-well plates in a DMEM supplemented with $10 \%$ fetal bovine serum, $1 \%$ penicillin/ streptomycin/neomycin, $1 \%$ sodium pyruvate and $1 \%$ L-glutamine. They were cultured for 6 days by replacing the medium every $2-3$ days. The incubation of LNC-C12 consisted of replacing the medium by Hanks' balanced salt solution in which the compound was diluted to 2,5 and $10 \mathrm{mg} \cdot \mathrm{ml}^{-1}$. After $1 \mathrm{~h}$ at $37^{\circ} \mathrm{C}, 5 \% \mathrm{CO}_{2}$, the cells' incubation media was removed and diluted fivefold in $95 \%$ acetonitrile $15 \%$ formic acid, and the cells were scraped in $20 \%$ water $/ 76 \%$ acetonitrile $/ 4 \%$ formic acid. After centrifugation $\left(13,000 \times g, 10 \mathrm{~min}, 4^{\circ} \mathrm{C}\right)$, HPLC tandem mass spectrometry was performed on supernatants to detect creatine and dodecyl creatine ester in the cell lysates.

\section{HPLC tandem mass spectrometry} identification of dodecyl creatine ester

Liquid chromatography (an HPLC system, LC-20AD Shimadzu, Marne-la-Vallée, France) with a $2.0 \times 150-\mathrm{mm}$ Uptisphere $^{\circledR}$ Diol HPLC column (UP6OH; Interchim, Montluçon, France) was used for elution of dodecyl creatine ester and creatine. The mobile phase was isocratic at 40/60 (detection of creatine) or 20/80 (detection of dodecyl creatine ester) solvent $A / B$ (where solvent $A$ was $\mathrm{H}_{2} \mathrm{O}$ containing $0.1 \%$ formic acid and solvent $\mathrm{B}$ was acetonitrile containing $0.1 \%$ formic acid); the flow rate was $0.4 \mathrm{ml} / \mathrm{min}$. Analyte $(10 \mu \mathrm{l})$ was injected onto the column placed in an oven at $40^{\circ} \mathrm{C}$. The total run time was 6 min. 
Table 1. Uptake of dodecyl creatine ester associated with lipid nanocapsules, in blood-brain barrier endothelial cells and blood-brain barrier glial cells, during translocation of dodecyl creatine ester encapsulated in lipid nanocapsules throughout the blood-brain barrier.

\begin{tabular}{lll} 
LNC-C12 concentration (mg. $\mathbf{m l}^{-1}$ ) & Endothelial cells (nmoles/mg proteins) & Astroglial cells (nmoles/mg proteins) \\
\hline 2 & $0.551 \pm 0.14$ & $2.550 \pm 2.45$ \\
\hline 5 & $0.818 \pm 0.43$ & $2.262 \pm 1.25$ \\
10 & $0.870 \pm 0.31$ & $1.394 \pm 0.96$
\end{tabular}

The amount of dodecyl creatine ester as nmoles per mg protein quantified in the blood-brain barrier endothelial cell lysate and blood-brain barrier glial cell lysate after an incubation with 2, 5 or $10 \mathrm{mg}^{\mathrm{ml}}{ }^{-1}$ dodecyl creatine ester encapsulated in lipid nanocapsules.

LNC-C12: Dodecyl creatine ester encapsulated in lipid nanocapsules.

Tandem mass spectrometry (Finnigan ${ }^{\mathrm{TM}}$ TSQ Quantum Discovery with Xcalibur and LC Quan softwares; Thermo, Illkirch, France) in positive electrospray mode was used for detection. Spray voltage was $3.0 \mathrm{kV}$, and sheath and auxiliary gas pressures were 50 and 20 a.u., respectively. The in-source collision-induced dissociation energy was fixed at $12 \mathrm{~V}$ and the capillary temperature was $350^{\circ} \mathrm{C}$. The tube lens (creatine: 100 a.u.; dodecyl ester: 110 a.u.) and collision energy (creatine: 10 a.u.; dodecyl ester: 25 a.u.) values were optimized for each compound. Multiple reaction monitoring was used for the detection of the ion transitions: $\mathrm{m} / \mathrm{z} 132.156$ to 90.185 (creatine) or $\mathrm{m} / \mathrm{z} 300.285$ to 90.125 (dodecyl creatine ester). The standard curves showed linearity for creatine over a range of $0.05-10$ and $0.01-05 \mu \mathrm{g} \cdot \mathrm{ml}^{-1}$ for dodecyl creatine ester. Creatine fatty esters and creatine concentrations and amounts were determined in each compartment and in endothelial cells, astroglial cells and fibroblast lysates. The amount of creatine fatty esters and the amount of creatine were standardized to the amount of protein in each lysate.

\section{Results \& discussion}

Here, we show that the LNC-C12 were incorporated into brain endothelial cells since we found $0.55 \pm 0.14,0.82 \pm 0.43$ and $0.87 \pm 0.31$ nmoles per $\mathrm{mg}$ of protein of dodecyl creatine ester in the endothelial cell lysates after a 60-min incubation with 2, 5 and $10 \mathrm{mg} \cdot \mathrm{ml}^{-1}$ of LNC-C12, respectively (Table 1). No difference was detected between the three concentrations of LNC-C12. Some LNC-C12 were also able to diffuse through the BBB model and enter the glial cells (Table 1) since almost 2 nmoles per $\mathrm{mg}$ of protein of dodecyl creatine ester was found in the cell lysates for the three concentrations. This means that the dodecyl creatine ester had been protected from endothelial cell degradation by crossing the $\mathrm{BBB}$. An interesting point is that even dodecyl creatine ester alone is also able to cross the $\mathrm{BBB}$, but ester levels are almost twofold higher in glial cells than in endothelial cells when treated with LNC-C12, whereas the reverse is true with the ester alone. This suggests that the LNCs would favor this

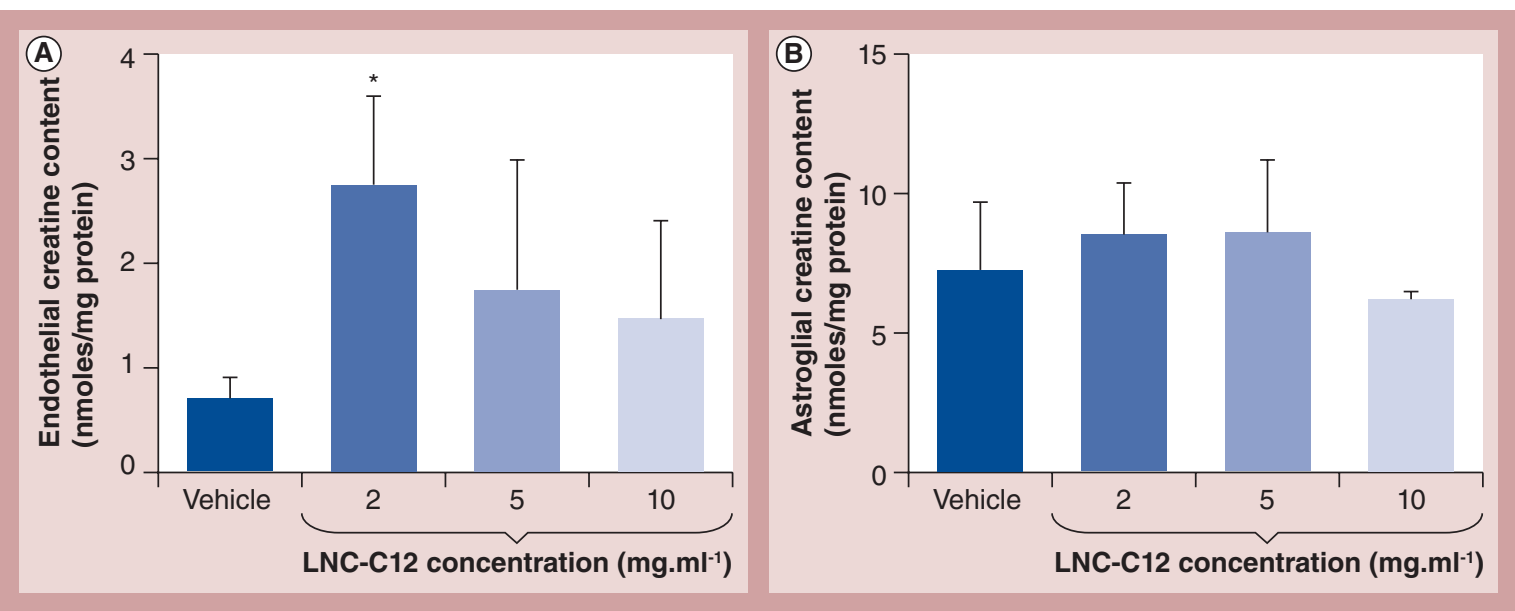

Figure 1. Transport of dodecyl creatine ester encapsulated in lipid nanocapsules across an in vitro cell-based blood-brain barrier model. Creatine content in the blood-brain barrier (A) endothelial cell lysate and (B) astroglial cell lysate. The amount of creatine is in nmoles per mg of protein quantified in blood-brain barrier endothelial cell and astroglial lysates after a 60 -min incubation with 2, 5 or $10 \mathrm{mg}^{\mathrm{ml}} \mathrm{m}^{-1} \mathrm{LNC}-\mathrm{C} 12$ compared with the vehicle alone. The error bars represent the standard deviation.

${ }^{*} p<0.05$ (analysis of variance plus Dunnett's post-test).

LNC-C12: Dodecyl creatine ester encapsulated in lipid nanocapsules. 
passage to the brain and validates the applicability of LNC-C12 to cross the BBB.

Not all of the tested conditions increased LY permeability, an internal standard of BBB integrity, as its values were below the limit range of $5 \times 10^{-6} \mathrm{~cm} \cdot \mathrm{s}^{-1}[14]$ $\left(0.48 \pm 0.10 \times 10^{-6}, 0.41 \pm 0.02 \times 10^{-6}\right.$ and $0.82 \pm 0.57 \times 10^{-6} \mathrm{~cm} \cdot \mathrm{s}^{-1}$ for 2,5 and $10 \mathrm{mg} \cdot \mathrm{ml}^{-1}$ LNC-C12, respectively, compared with the vehicle alone: $\left.0.39 \pm 0.17 \times 10^{-6} \mathrm{~cm} \cdot \mathrm{s}^{-1}\right)$, suggesting that the LNC-C12 did not compromise the integrity of the in vitro cell-based rat $\mathrm{BBB}$ model and that the cell monolayer was intact.

When we quantified the creatine released from the dodecyl creatine ester, we showed that $2 \mathrm{mg} \mathrm{ml}^{-1}$ LNC-C12 induced a slight increase of creatine content in the brain endothelial cell lysate ( $p<0.05$, Figure $1 \mathrm{~A})$. However, this was not the same for the higher concentrations and we could not find any dose-response correlation. No significant change was observed in the glial lysate creatine pool (Figure 1B). However, our experiments to analyze the esterase activity showed that they were functional so the glial cells were able to cleave the ester. Despite this lack of evidence of an increase in creatine in glial cells, we detected an increase of creatine in the apical and basolateral cells' incubation media. Albeit detectable, this increase was not quantifiable because it was under the lowest limit of quantification of the bioanalytical method.

First, this indicates that as we tested the LNC-C12 in a nonpathological BBB model, the creatine produced by the enzymatic conversion of dodecyl creatine ester could have been excreted in extracellular media through the functional SLC6A8, preventing us from determining an increase in creatine content in glial cells. Second, as the metabolic pathways in these cells were functional, the creatine released from the dodecyl creatine ester could have been involved in the metabolic pathway of the creatine/phosphocreatine shuttle. This is why we studied internalization of LNC-C12 in a pathological human fibroblast model expressing a nonfunctional SLC6A8.

To confirm the relevance of our strategy, since our interest resided in developing a new pharmacological strategy to treat creatine transporter deficiency, we evaluated the release of dodecyl creatine ester and its conversion to creatine in human fibroblasts lacking functional creatine transporter. First, we demonstrated that LNC-C12 was equivalently incorporated in fibroblasts from both control patients $(28.9 \pm 0.68$ and $22.0 \pm 1.27 \%$ of initial quantity) and patients with creatine transporter deficiency: DTp1 $(27.7 \pm 1.85$ and $19.2 \pm 0.86 \%)$, VLp2 $(20.3 \pm 8.12$ and $19.3 \pm 1.18 \%)$ and CTp3 $(8.85 \pm 0.34$ and $18.2 \pm 0.89 \%)$ at concentrations of 5 and $10 \mathrm{mg} \cdot \mathrm{ml}^{-1}$, respectively. This

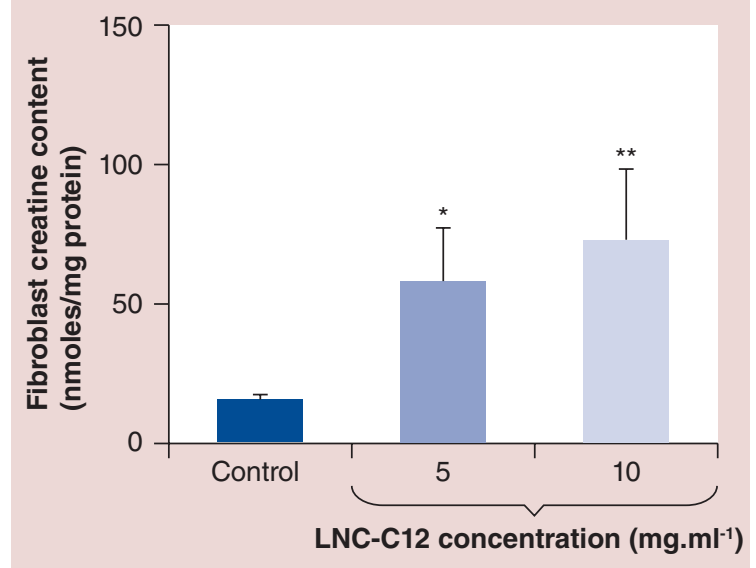

Figure 2. Creatine content in human fibroblasts of a control patient. A $60-\mathrm{min}$ incubation of 5 or $10 \mathrm{mg}^{\mathrm{m}} \mathrm{ml}^{-1}$ LNC-C12 led to a significant increase compared with the vehicle alone in creatine content in fibroblasts of the control patient. The error bars represent standard deviation.

${ }^{*} \mathrm{p}<0.05,{ }^{* *} \mathrm{p}<0.005$ (analysis of variance plus Dunnett's post-test).

LNC-C12: Dodecyl creatine ester encapsulated in lipid nanocapsules.

indicates that the LNC-C12 did not depend on creatine transporter to enter the cells. A significant increase in creatine content was detected in both nonpathological and pathological fibroblasts (Figures 2 \& 3). This led

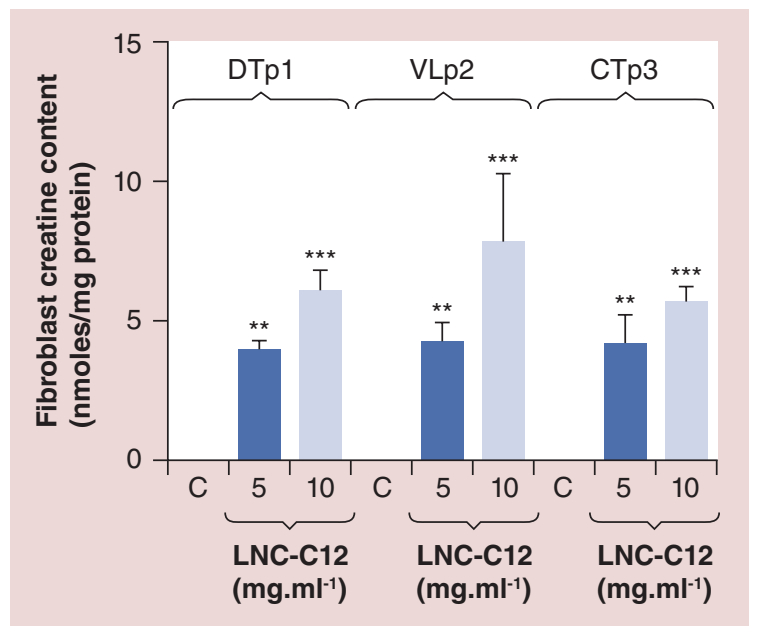

Figure 3. Significant increase of creatine content in human fibroblasts showing SLC6A8 deficiency.

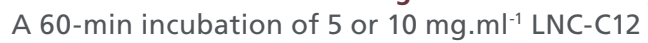
(concentration of LNC-C12 in $\mathrm{mg}^{\mathrm{ml}} \mathrm{m}^{-1}$ ) led to a significant increase compared with the control corresponding to untreated cells in creatine content in fibroblasts of patients with nonfunctional creatine transporter. The error bars represent standard deviation.

$* * p<0.005, * * * p<0.001$ (analysis of variance plus

Dunnett's post-test).

C: Control; LNC-C12: Dodecyl creatine ester

encapsulated in lipid nanocapsules. 
to the assumption that, once the LNC-C12 entered the fibroblasts, all or part of the dodecyl creatine ester released was biotransformed to creatine by esterases, which points to the great potential of this system in this particular therapeutic context. The same positive results were obtained with the dodecyl creatine ester alone, but it cannot be used in human therapy due to its degradation in the plasma.

These results suggest that our dodecyl creatine ester delivery system seems to be of particular interest in the pathological context of creatine transporter deficiency. Addition of Transcutol to the formulation is the only way to solubilize the dodecyl creatine ester, which has an amphiphilic chemical structure.

LNC-C12 cross the BBB in vitro and deliver dodecyl creatine ester to the astrocytes in the brain parenchyma compartment. Although it did not increase the intracellular creatine pool in nonpathological brain cells, LNC-C12 limited the efflux of creatine outside of these cells compared with the dodecyl creatine ester alone. By contrast, in human fibroblasts from patients with creatine transporter deficiency, LNC-C12 increased levels of creatine, the essential energy compound. We strongly believe that LNC-C12 should be further investigated in in vivo models to assess the protection of dodecyl creatine ester from esterases. This formulation would be of particular interest in a two-step therapeutic strategy: first, the LNC-C12 would cross the BBB and could be delivered itself or just release dodecyl creatine ester into the brain parenchyma; and second, in both cases, LNC-C12 or dodecyl creatine ester would penetrate neuronal cells and increase their creatine content, thus restoring neuronal functions in creatine transporter deficiency.

\section{Future perspective}

This study reports the first double strategy to overcome the BBB and increase the delivery of dodecyl creatine ester into the brain parenchyma. We describe here the in vitro proof of concept for the treatment of the creatine transporter deficiency by LNC-C12. In the future, it will be of major interest to evaluate the therapeutic efficiency of this new device in an in vivo model of the pathology (SLC6A $8^{-1-}$ knockout mouse model [19]). The LNC-C12 could be fluoro- or radiolabeled in order to be detected in vivo and follow the therapeutic efficiency of the dodecyl creatine ester.

\section{Acknowledgements}

The authors thank Mickaël Kempf for his liquid chromatographytandem mass spectrometry support and the patients included in this study.

Financial \& competing interests disclosure This work was supported by the Fondation Jérôme Lejeune and by the CEA, Life Division of Sciences, Institut of Biology and Technology of Saclay (Gif-sur-Yvette, France). The authors have no other relevant affiliations or financial involvmement with any organization or entity with a financial interest in or financial conflict with the subject matter or materials discussed in the manuscript.

No writing assistance was utilized in the production of this manuscript.

\section{Executive summary}

- The surfactant Transcutol ${ }^{\circledR}$ (Gattefossé SAS, Saint-Priest, France) dissolves the dodecyl creatine ester, an amphiphilic chemical structure, at ambient temperature and thus led to the incorporation of the creatine prodrug in the shell of lipid nanocapsules (LNCs) with suitable intravenous injection properties (size: $48.31 \pm 1.77 \mathrm{~nm}$; polydispersity index: $0.07 \pm 0.01$; and zeta-potential: $-0.17 \mathrm{mV}$ ).

- This new device (dodecyl creatine ester encapsulated in LNCs) crosses the blood-brain barrier and delivers dodecyl creatine ester to the brain parenchyma, even in the context of a nonfunctional creatine transporter.

- In human fibroblasts from patients with creatine transporter deficiency, dodecyl creatine ester encapsulated in LNCs increased levels of creatine - the essential energy compound.

\section{References}

Papers of special note have been highlighted as:

- of interest

- of considerable interest

1 Stockler S, Schutz PW, Salomons GS. Cerebral creatine deficiency syndromes. Clinical aspects, treatment and pathophysiology. Subcell. Biochem. 46, 149-166 (2007).

- Overview of the clinical features of creatine deficiency syndromes.
2 Schulze A. Creatine deficiency syndromes. Mol. Cell. Biochem. 244(1), 143-150 (2003).

- First study to report a link between the defect in the $\mathrm{X}$-linked creatine transporter and developmental delay, mild epilepsy and several language impairments.

3 Degrauw TJ, Cecil KM, Byars AW, Salomons GS, Ball WS, Jakobs C. The clinical syndrome of creatine transporter deficiency. Mol. Cell. Biochem. 244(1-2), 45-48 (2003). 
4 Poo-Arguelles P, Arias A, Vilaseca Ma et al. X-Linked creatine transporter deficiency in two patients with severe mental retardation and autism. J. Inherit. Metab. Dis. 29(1), 220-223 (2006).

5 Van De Kamp JM, Pouwels PJ, Aarsen FK et al. Long-term follow-up and treatment in nine boys with X-linked creatine transporter defect. J. Inherit. Metab. Dis. 35(1), 141-149 (2012).

6 Ohtsuki S, Tachikawa M, Takanaga H et al. The bloodbrain barrier creatine transporter is a major pathway for supplying creatine to the brain. J. Cereb. Blood Flow Metab. 22 (11), 1327-1335 (2002).

-. First study to report the major contribution of creatine transporter at the blood-brain barrier in supplying creatine to the brain.

7 Braissant O, Henry H, Beard E, Uldry J. Creatine deficiency syndromes and the importance of creatine synthesis in the brain. Amino Acids 40 (5), 1315-1324 (2011).

8 Lunardi G, Parodi A, Perasso L et al. The creatine transporter mediates the uptake of creatine by brain tissue, but not the uptake of two creatine-derived compounds. Neuroscience 142(4), 991-997 (2006).

9 Trotier-Faurion A, Dezard S, Taran F, Valayannopoulos V, De Lonlay P, Mabondzo A. Synthesis and biological evaluation of new creatine Fatty esters revealed dodecyl creatine ester as a promising drug candidate for the treatment of the creatine transporter deficiency. J. Med. Chem. 56(12), 5173-5181 (2013).

-. Reports a new promising drug candidate for the treatment of the creatine transporter deficiency.

10 Lamprecht A, Bouligand Y, Benoit JP. New lipid nanocapsules exhibit sustained release properties for amiodarone. J. Control. Release 84(1-2), 59-68 (2002).

11 Laine AL, Huynh NT, Clavreul A et al. Brain tumour targeting strategies via coated ferrociphenol lipid nanocapsules. Eur. J. Pharm. Biopharm. 81(3), 690-693 (2012).
12 Huynh NT, Passirani C, Saulnier P, Benoit JP. Lipid nanocapsules: a new platform for nanomedicine. Int. J. Pharm. 379(2), 201-209 (2009).

- Describes the promising nanovector for oral administration.

13 Roger E, Lagarce F, Benoit JP. Development and characterization of a novel lipid nanocapsule formulation of Sn38 for oral administration. Eur. J. Pharm. Biopharm. 79(1), 181-188 (2011).

14 Lacombe $\mathrm{O}$, Videau $\mathrm{O}$, Chevillon $\mathrm{D}$ et al. In vitro primary human and animal cell-based blood-brain barrier models as a screening tool in drug discovery. Mol Pharm 8(3), 651-663 (2011).

15 Heurtault B, Saulnier P, Pech B, Proust JE, Benoit JP. A novel phase inversion-based process for the preparation of lipid nanocarriers. Pharm. Res. 19(6), 875-880 (2002).

16 Brun E, Carriere M, Mabondzo A. In vitro evidence of dysregulation of blood-brain barrier function after acute and repeated/long-term exposure to $\mathrm{TiO}(2)$ nanoparticles. Biomaterials 33(3), 886-896 (2012).

17 Valayannopoulos V, Bakouh N, Mazzuca M et al. Functional and electrophysiological characterization of four nontruncating mutations responsible for creatine transporter (SLC6A8) deficiency syndrome. J. Inherit. Metab. Dis. 36(1), 103-112 (2013).

18 Valayannopoulos V, Boddaert N, Chabli A et al. Treatment by oral creatine, L-arginine and L-glycine in six severely affected patients with creatine transporter defect. J. Inherit. Metab. Dis. 35(1), 151-157 (2012).

19 Skelton Mr, Schaefer Tl, Graham Dl et al. Creatine transporter (CrT; Slc $6 a 8)$ knockout mice as a model of human CrT deficiency. PLoS ONE 6(1), e16187 (2011).

-. First study to report the in vivo model of the creatine transporter deficiency.

\section{Patent}

101 Dezard D, Taran F, Trotier-Faurion A, Mabondzo A: EP-2692719A1 (2014). 